\title{
KAJIAN LOKASI POTENSIAL PERUMAHAN DAN PERMUKIMAN DI KABUPATEN PESAWARAN DENGAN SISTEM INFORMASI GEOGRAFIS (SIG)
}

\author{
Nadian Maretta ${ }^{1}$, Citra Dewi ${ }^{2}$, Fauzan Murdapa ${ }^{3}$, Eko Rahmadi ${ }^{4}$ \\ 1,2,3,4 Program Studi Teknik Geodesi, Fakultas Teknik Universitas Lampung \\ J1 Prof. Dr. Sumantri Brojonegoro No.1 Bandar Lampung 35145 \\ Jurusan Teknik Geofisika, FT UNILA
}

Corresponding author: nadianmaretta17@gmail.com

Manuscript received: June 30, 2019; revised: August 1, 2019;

Approved: October 31, 2019; available online: November 11, 2019

\begin{abstract}
Abstrak - Kabupaten Pesawaran sebagai kabupaten baru yang dibentuk pada tahun 2007, Kabupaten Pesawaran mengalami perkembangan jumlah penduduk yang pesat maka kebutuhan lahan perumahan dan permukiman akan bertambah. Oleh karena itu perlu ada perencanaan yang matang dalam menentukan lokasi pengembangan perumahan dan permukiman di Kabupaten Pesawaran. Penelitian ini bertujuan: 1) Mengetahui bobot untuk setiap parameter yang digunakan dalam menentukan tingkat potensial lahan pengembangan perumahan dan permukiman dengan metode AHP (Analytic Hierarchy Process). 2) Menentukan tingkat potensial lahan di Kabupaten Pesawaran untuk pengembangan perumahan dan permukiman. Metode yang digunakan adalah metode AHP (Analytcal Hierarchy Process), metode yang digunakan dalam analisis spasial menggunakan SIG (Sistem Informasi Geografis). Hasill penelitian dengan perhitungan AHP menunjukan parameter yang paling dominan adalah aksesibilitas. Alasannya, aksesibilitas akan mempengaruhi kemudahan pelayanan transportasi dan keterjangkauan jarak.. Hasil analisis menggunakan SIG menghasilkan 5 Lokasi potensial untuk pengembangan perumahan dan permukiman di Kabupaten Pesawaran yaitu sangat berpotensi (13456.50 ha), berpotensi (47941.61 ha), cukup berpotensi (47362.11 ha), kurang berpotensi (16107.09 ha), dan tidak berpotensi ( $8251.13 \mathrm{ha})$.
\end{abstract}

\begin{abstract}
Pesawaran District, as a new district which was established in 2007, has experienced a rapid growth in population. As the population increases, housing and residential land needs will increase. Therefore, there should be a careful planning in determining the location of housing and settlement development in Pesawaran District. This study aims to: 1) Know the weight for each parameter used in determining the level of potential for a land for the development of housing and residential areas with method AHP 2) Know the potential level of land in Pesawaran District for the development of housing and settlements. The method used is AHP (Analytic Hierarchy Process), while the method by spatial analysis using GIS (Geographic Information System). The results of the study with AHP calculations show that the most dominant parameter is accessibility. The reason is, accessibility will affect the ease of transportation services and affordability of distance. The results of the analysis using GIS resulted in 5 potential locations for the development of residential and residential areas in Pesawaran District which are very potential (13456.50 ha), potential (47941.61 ha), quite potential (47362.11 ha), less extensively potential (16107.09 ha), and no potential (8251.13 ha).
\end{abstract}

Keywords: potential location, housing, settlement, AHP, geographic information system.

How to cite this article:

Maretta, N., Dewi, C., Murdapa, F., dan Raharjo, E., 2019, Kajian Lokasi Potensial Perumahan dan Permukiman di Kabupaten Pesawaran dengan Sistem Informasi Geografis (SIG), Jurnal Geofisika Eksplorasi, 5 (3) p.185-192. doi: 10.23960/jge.v5i3.33

\section{PENDAHULUAN}

Sebagai kabupaten baru yang dibentuk pada tahun 2007, Kabupaten Pesawaran mengalami perkembangan jumlah penduduk yang pesat. Dengan semakin meningkatnya jumlah penduduk maka berbagai kegiatan aktivitas pembangunan 
menjadi bertambah dan berdampak pada meningkatnya kebutuhan lahan. Salah satu kebutuhan lahan yang diperlukan penduduk adalah untuk perumahan dan permukiman.Bertambahnya permintaan lahan untuk perumahan dan permukiman bisa menyebabkan lahan pertanian akan semakin terancam yang semula bidang pertanian menjadi non pertanian misalnya koversi lahan sawah ke lahan permukiman.

Menurut Agus Sindelaras (2011) menyatakan terjadi koversi lahan di Desa Gedong Tataan, Kecamatan Gedong Tataan, Kabupaten Pesawaran disebabkan oleh pembangunan perumahan atau industri di kawasan tersebut. Terlihat luas lahan awal sawah irigasi sekitar 35 ha kini telah berkurang menjadi sekitar 21 ha, Seiring dengan bertambahnya kebutuhan lahan untuk perumahan atau industri di daerah tersebut. Berdasarkan permasalahan tersebut diperlukan perencanaan yang matang dan terarah agar tidak terjadi koversi lahan yang semakin bertambah.

Secara Teknis perencanaan pengembangan kawasan perumahan dan permukiman ada beberapa parameter yang meliputi : a) sumberdaya air, b) kemudahan lahan, c) kemiringan lereng, d) aksesibilitas, e) penggunaan lahan, f) fasilitas umum, serta g) kerentanan bencana.

Pertimbangan parameter tersebut diperlukan untuk menentukan lokasi potensial yang bisa dikembangkan menjadi kawasan perumahan dan permukiman, karena setiap kawasan memiliki kemampuan yang terbatas sekaligus berbeda antara satu kawasan dengan kawasan lainnya.

Tujuan dalam penelitian ini adalah sebagai berikut:

1. Mengetahui bobot untuk setiap parameter yang digunakan dalam menentukan tingkat potensial lahan pengembangan perumahan dan permukiman dengan metode AHP (Analytic Hierarchy Process)

2. Menentukan tingkat potensial lahan di Kabupaten Pesawaran untuk pengembangan perumahan dan permukiman.

\section{TINJAUAN PUSTAKA}

\subsection{Perumahan dan permukiman}

Berdasarkan Undang-Undang No. 1 Tahun 2011 tentang Perumahan dan Permukiman. Perumahan adalah kelompok rumah yang berfungsi sebagai lingkungan tempat tinggal atau lingkungan hunian yang dilengkapi dengan sarana dan prasarana lingkungan. Perumahan merupakan salah satu bentuk sarana hunian yang memiliki kaitan yang sangat erat dengan masyarakatnya. Sedangkan permukiman adalah bagian dari lingkungan hidup di luar kawasan lindung, baik berupa kawasan perkotaan maupun kawasan perdesaan, yang berfungsi sebagai lingkungan tempat tinggal.

Menurut Djemabut (1977) permukiman adalah kawasan perumahan lengkap dengan prasarana lingkungan, prasarana umum, dan fasilitas umum dan fasilitas sosial yang mengandung keterpaduan kepentingan dan keselarasan pemanfaatan sebagai lingkungan kehidupan.

Menurut Budihardjo mengisyaratkan bahwa penentuan lokasi perumahan yang baik perlu memperhatikan hal-hal sebagai berikut:

1. Ditinjau dari segi teknis pelaksanaannya Mudah mengerjakannya dalam arti tidak banyak pekerjaan cut \& fill, Bukan daerah bencana, mudah dicapai tanpa hambatan yang berarti, mudah mendapatkan sumber air bersih, listrik, pembuangan air (drainage), sekolah, pasar, puskesmas dan lain-lain.

2. Ditinjau dari segi tata guna tanah

Tidak merusak lingkungan yang ada, sejauh mungkin dipertahankan tanah yang berfungsi sebagai reservoir air tanah, penampung air hujan dan penahan air laut, tanah secara ekonomis telah sukar dikembangkan secara produktif, misal: (a) bukan daerah persawahan, (b) 
bukan daerah-daerah kebun, (c) Bukan daerah usaha seperti, pabrik/industri;

3. Dilihat dari segi kesehatan dan kemudahan:

Lokasi sebaiknya jauh dari lokasi pabrik yang dapat mendatangkan polusi, lokasinya sebaiknya tidak terlalu terganggu oleh kebisingan, lokasinya sebaiknya dipilih yang udaranya masih sehat, lokasi sebaiknya mudah dicapai dari tempat kerja penghuninya.

4. Ditinjau dari segi politis dan ekonomis Menciptakan kesempatan kerja dan berusaha bagi masyarakat sekelilingnya; Mudah dalam pemasarannya karena lokasinya disukai oleh calon pembeli dan dapat mendatangkan keuntungan yang bagi developernya.

\subsection{AHP (Analytical Hierarchy Process)}

AHP digunakan untuk mengkaji permasalahan yang dimulai dengan mendefenisikan permasalahan tersebut secara seksama kemudian menyusunnya ke dalam suatu hirarki. Proses dalam AHP bergantung pada imajinasi, pengalaman, dan pengetahuan untuk menyusun hirarki suatu permasalahan dan bergantung pada logika dan pengalaman untuk memberi pertimbangan.

Menurut Saaty (1994), prinsip-prinsip yang harus dipahami dalam menyelesaikan permasalahan menggunakan AHP, yaitu :

1. Penyusunan Hirarki

Merupakan langkah penyederhanaan masalah ke dalam bagian yang menjadi elemen pokoknya, kemudian ke dalam bagian-bagiannya lagi, dan seterusnya secara hirarki agar lebih jelas, sehingga mempermudah pengambilan keputusan untuk menganalisis dan menarik kesimpulan terhadap permasalahan tersebut.

2. Menentukan Prioritas

AHP melakukan perbandingan berpasangan (pairwaise comparison) antara dua elemen pada tingkat yang sama. Kedua elemen tersebut dibandingkan dengan menimbang tingkat preferensi elemen yang satu terhadap elemen yang lain berdasarkan kriteria tertentu.

3. Konsistensi Logis

Konsistensi logis merupakan prinsip rasional dalam AHP. Konsistensi berarti ada dua hal, yaitu :

a. Pemikiran atau objek yang serupa dikelompokkan menurut homogenitas dan relevansinya

b. Relasi antara objek yang didasarkan pada kriteria tertentu, saling membenarkan secara logis.

\subsection{Sistem Informasi Geografis (SIG)}

Merupakan suatu sistem berbasis komputer untuk menangkap (capture), menyimpan (store), memanggil kembali (retrieve), menganalisis dan mendisplay data spasial (Aeronoff 1995).

SIG adalah suatu sistem basis data dengan kemampuan khusus untuk menangani data yang bereferensi keruangan (spasial) bersamaan dengan seperangkat operasi kerja (Barus dan Wiradisastra, 2000).

Secara umum, sesuai dengan datanya terdapat dua jenis fungsi analisis di dalam SIG; fungsi analisis spasial dan atribut (basis data atribut). Fungsi analisis atribut (non-spasial) antara lain terdiri dari operasioperasi dasar Database Management System (DBMS) beserta perluasannya (Eddy Prahasta 2009).

\section{METODELOGI PENELITIAN}

Metode yang digunakan untuk menentukan lokasi potensial pengembangan perumahan dan permukiman adalah dengan analisis spasial menggunakan SIG (Sistem Informasi Geografi) sedangkan metode yang digunakan untuk mengetahui parameter yang paling dominan dalam pemilihan lokasi potensial pengembangan perumahan dan permukiman adalah dengan pembobotan menggunakan AHP (Analytical Hierarchy Process).

Ada 2 data yang dikumpulkan dalam penelitian ini yaitu data primer dan 
sekunder. Pengumpulan data primer merupakan pengumpulan data yang dilakukan sendiri di lapangan melalui wawancara, peninjauan lokasi atau pengamatan, dokumentasi, perhitungan, maupun kuesioner kepada responden. Data Primer dikumpulkan melalui kuesioner perbandingan berpasangan dan wawancara kepada sejumlah 15 informan. Informan yang dipilih adalah Pegawai Bappeda Kabupaten Pesawaran di Bidang Tata Ruang, Pegawai PUPR Kabupaten Pesawaran, dan Pengembang (Developer). Mereka dinilai mengenal Kawasan yang tepat untuk di jadikan kawasan perumahan dan permukiman.

Data sekunder adalah data yang diperoleh dari instansi terkait. Dalam penelitian ini pengumpulan data di lakukan di Bappeda Kabupaten Pesawaran dalam bentuk shp dan Badan Perlindungan Kawasan Hutan (BPKH) XX dalam bentuk jpeg dan telah mempunyai sistem koordinat yang sama yaitu UTM dan WGS 48s. Data sekunder yang dikumpulkan adalah peta sumberdaya air, peta kemudahan lahan, peta kemiringan lereng, peta aksesbilitas, peta penggunaan lahan, peta fasilitas umum, serta peta kerawanan bencana.

\subsection{Memilih Parameter Paling Dominan Dengan Metode AHP}

Hasil dari penyebaran 15 kuisioner di hitung melalui metode AHP (Analytical Hierarchy Process). Pengolahan data dengan metode AHP dalam penelitian ini meliputi :

1. Perhitungan eigenvector.

Nilai Eigenvector diperoleh dengan rumus Eigenvector $=\mathrm{A} 1 / \mathrm{n}$

2. Perhitungan Consistency Ratio (CR) $\mathrm{CR}=C I / R I$

Untuk mengetahui tingkat konsistensi responden, diharus melakukan perhitungan (consistency index/CI) sebagai berikut:

$$
C I=\frac{\lambda \mathrm{maks}-n}{n-1}
$$

Menurut Saaty (1994), Random Indeks (RI) matriks berukuran 1 sampai dengan 12 (Tabel 1). Dalam hal ini penilaian dapat dikatakan konsisten jika nilai CR (consistency ratio) kurang dari 0,1 .

3. Perhitungan bobot faktor

Bobot faktor diperoleh dengan menghitung nilai rata-rata eigenvector dari semua informan

\subsection{Analisis Spasial}

Penentuan lokasi potensial pengembangan kawasan perumahan dan permukiman dilakukan dengan menggunakan SIG (Sistem Informasi Geografi). Data dikumpulkan dari berbagai dinas berupa peta-peta dasar dari setiap parameter. Peta dasar tersebut di beri bobot sesuai hasil perhitungan metode ahp dan dilakukan teknik overlay sehingga didapatkan peta potensi pengembangan kawasan perumahan dan permukiman.

\section{HASIL DAN PEMBAHASAAN}

\subsection{Analisis Parameter}

Dari hasil perhitungan dengan metode ahp dapat diketahui nilai rasio konsistensi (CR) $\quad<0,1$ untuk semua kuisioner (alternatif). Nilai CR ke tujuh parameter di dapatkan sebesar 0,087. Dari nilai CR tersebut diketahui bahwa nilai bobot dari tujuh parameter sudah dapat digunakan untuk menentukan tingkat potensi lahan untuk kawasan perumahan dan permukiman.

Parameter Aksesbilitas memiliki bobot paling besar sebesar 0,25 faktor aksesibilitas sebagai pengaruh utama dalam memilih lokasi tempat tinggal yaitu kemudahan pelayanan transportasi dan keterjangkauan jarak.

Parameter Kerawanan Bencana menempati urutan kedua dengan bobot sebesar 0,23 yang dianggap lebih penting dari parameter lainnya, Hal ini sesuai 
dengan UU No 1 Tahun 2011 tentang Perumahan dan Kawasan Permukiman yang menyebutkan bahwa dalam perencanaan kawasan permukiman maupun perumahan harus mencakup aspek mitigasi bencana.

Parameter kemiringan lereng menempati ururan ketiga dengan bobot sebesar 0,17 alasannya karena setiap kawasan memiliki kondisi yang berbedabeda, jika kemiringan lebih dari $40 \%$ bisa menyebabkan tanah yang tidak stabil dan bahaya tanah longsor.

Parameter kemudahan lahan menempati urutan keempat dengan bobot sebesar 0,12. Kemudahan lahan penting untuk menjadi parameter penentuan perumahan karena dapat mengetahui dimanakah kawasan yang memiliki lahan yang mudah dikerjakan.

Parameter penggunaan lahan menepati urutan kelima dengan bobot sebesar 0,09. Penggunaan lahan yang tidak sesuai dengan kamampuannya dapat menyebabkan kerusakan lahan karena lahan yang mempunyai kualitas terbaik untuk pertanian belum tentu mempunyai kualitas yang baik untuk lokasi lahan terbangun. Pengubahan lahan pertanian menjadi lahan terbangun harus dikendalikan agar keseimbangan alam tetap terjaga.

Parameter fasilitas umum menempati urutan keenam dengan bobot sebesar 0,07 artinya fasilitas umum kurang dipertimbangkan dalam menentukan lokasi perumahan,

Parameter ketersedian air menempati urutan terakhir dengan bobot sebesar 0,06 karena daerah pesawaran mempunyai ketersediaan air yang baik hampir di seluruh kecamatannya itulah sebabnya menjadi parameter yang kurang di pertimbangkan.

\subsection{Analisis Potensi Pengembangan Kawasan Perumahan dan Permukiman}

Dalam analisis penentuan lokasi potensial pengembangan kawasan perumahan dan permukiman ditinjau dari tujuh parameter, setiap parameter diberi skor yang didapat dari hasil perhitungan bobot dengan metode AHP. Penentuan nilai bobot berdasarkan hasil kuisioner dari ahli sehingga di dapatkan parameter yang paling mendukung untuk menentukan lokasi potensial perumahan dan permukiman. Hasil analisis didapatkan Peta Potensi Pengembangan Kawasan Perumahan dan Permukiman (Gambar 1).

Berdasarkan hasil analisis lokasi potensial pengembangan kawasan perumahan dan permukiman di Kabupaten Pesawaran memiliki lima (klasifikasi) yaitu sangat berpotensi, berpotensi, cukup berpotensi, kurang berpotensi, dan tidak berpotensi.

Kabupaten Pesawaran sebagian besar memiliki kawasan sangat berpotensi dengan luas 37987 ha dengan presentase 6\% sebagian besar berada di Kecamatan Gedong Tataan, Tegineneng dan Negeri Katon. Sedangkan kawasan berpotensi sebesar 241952 ha dengan presentase 39\% sebagian besar berada di Kecamatan Negeri Katon, Tegineneng dan Gedong Tataan. Kawasan cukup berpotensi sebesar 200753 ha dengan presentase 33\% sebagian besar berada di Kecamatan Gedong Tataan, Way Lima dan Padang Cermin. Kawasan kurang berpotensi sebesar 43620 ha dengan presentase sebesar 7\% sebagian besar berada di Kecamatan Way Lima, Padang Cermin, Punduh Pidada dan Kedondong. Kawasan tidak berpotensi sebesar 90476 ha dengan presentase sebesar 15\% kawasan tersebut berada di kecamatan Punduh Pidada, Way Lima dan Padang Cermin.

\subsection{Analisis Kesesuaian Potensial Pengembangan Perumahan dan Permukiman Terhadap Eksisting di Kabupaten Pesawaran}

Hasil overlay peta potensial pengembangan perumahan dan permukiman dengan peta eksisting perumahan dan permukiman menghasilkan Peta Kesesuaian Potensial Pengembangan Perumahan dan Permukiman Terhadap Eksisting di Kabupaten Pesawaran (Gambar 2). 
Berdasarkan pengolahan data masih ada banyak kawasan yang bisa dijadikan prioritas pembangunan perumahan dan permukiman lebih dari $50 \%$. Hampir semua kecamatan masuk dalam lokasi berpotensi, yang paling luas berada di Kecamatan Tegineneng, Negeri Katon, dan Gedong Tataan. Sedangkan Kecamatan Padang Cermin dan Punduh Pidada berada di lokasi tidak berpotensi.

Kecamatan Gedong Tataan sebagian Kawasan perumahan dan permukiman menempati lokasi sangat berpotensi sebesar $3333 \mathrm{Ha}$ dan masih ada kawasan yang berpotensi untuk dibangun menjadi kawasan perumahan dan permukiman sebesar 4827 ha. Kecamatan Negeri Katon masuk kedalam kawasan berpotensi masih ada kawasan yang dapat dibangun sebesar 47064 ha. Sedangkan Kecamatan Tegineneng mempunyai potensi untuk dibangun kawasan perumahan dan permukiman dengan luas 40879 ha.

\section{KESIMPULAN}

\subsection{Kesimpulan}

Dari hasi analisisa spasial dengan menggunakan Sistem Informasi Geografis untuk menentukan lokasi potensial Kawasan perumahan dan permukiman di Kabupaten Pesawaran, maka diperoleh kesimpulan sebagai berikut :

1. Hasil dari analisis pembobotan dengan metode AHP (analytic hierarchy process) diperoleh bobot setiap parameter sebesar Aksesbilitas 26\%, kerawanan bencana $23 \%$, kemiringan lereng $17 \%, 12 \%$ kemudahan dikerjakan, 9\% Pengunaan Lahan, 7\% fasilitas umum, dan $6 \%$ ketersediaan air.

2. Kabupaten Pesawaran sebagian besar memiliki kawasan sangat berpotensi dengan luas 37987 ha dengan presentase $6 \%$. Sedangkan kawasan berpotensi sebesar 241952 ha dengan presentase $39 \%$. Kawasan cukup berpotensi sebesar 200753 ha dengan presentase $33 \%$. Kawasan kurang berpotensi sebesar 43620 ha dengan presentase sebesar 7\%. Kawasan tidak berpotensi sebesar 90476 ha dengan presentase sebesar $15 \%$.

3. Tingkat Potensi pengembangan kawasan perumahan dan permukiman di Kabupaten Pesawaran paling luas berada di kecamatan Gedong Tataan sebesar 11698,32 ha, Tegineneng sebesar 20936,8 ha dan Negeri Katon sebesar 11105.65 ha.

4. Berdasarkan hasil analisis kesesuaian potensial pengembangan perumahan dan permukiman terhadap eksisting di kabupaten pesawaran kawasan yang bisa dijadikan prioritas pembangunan perumahan dan permukiman lebih dari $50 \%$. Hampir semua kecamatan masuk dalam lokasi berpotensi, yang paling luas berada di Kecamatan Tegineneng, Negeri Katon, dan Gedong Tataan.

\section{DAFTAR PUSTAKA}

Aeronoff S. 1995. Geographic Information System: A Management Perspective.:WLD Publication.

Badan Pusat Statistik Kabupaten Pesawaran. 2015, 'Statistik Penduduk Kabupaten Pesawaran'. Badan Pusat Statistik, Lampung.

Barus, B dan U. S. Wiradisastra. 2000. Sistem Informasi Geografi Sarana Manajemen Sumberdaya. Laboratorium Penginderaan Jauh dan Kartografi. Jurusan Tanah. Fakultas Pertanian. IPB. Bogor.

C, Djemabut, Blaang. 1977. Perumahan dan Permukiman Sebagai Kebutuhan Pokok. Jakarta: Yayasan Obor Indonesia. 
Budihardjo, Eko. 2009. Penataan Ruang dan Pembangunan Perkotaan. Bandung: Alumni

Prahasta, Eddy.2009. Sistem Informasi Geografis Konsep-Konsep Dasar. Bandung: Informatika Bandung.

Republik Indonesia. 2004. SNI 03-17332004 Tentang Tata Cara Perencanaan Lingkungan Perumahan Di Perkotaan.

Republik Indonesia. 2011. Undang-Undang No. 1 Tahun 2011 Tentang Perumahan Dan Kawasan Pemukiman.

Saaty, T.L., 1994. The Anallic Hierarchy Process. New York : McGraw-Hill.

Sindelaras, Agus. 2011. Pengawasan Pemerintah Dalam Alih Fungsi Lahan Di Kabupaten Pesawaran. Tesis. Lampung : Program Pascasarjana Magister Ilmu Pemerintahan Fakultas Ilmu Sosial Dan Ilmu Politik Universitas Lampung

\section{LAMPIRAN}

Tabel 1 Random Indeks AHP

\begin{tabular}{|l|l|l|l|l|l|l|l|l|l|l|l|}
\hline $\mathrm{n}$ & 2 & 3 & 4 & 5 & 6 & 7 & 8 & 9 & 10 & 11 & 12 \\
\hline $\mathrm{RI}$ & 0 & 0,58 & 0,9 & 1,12 & 1,24 & 1,32 & 1,41 & 1,45 & 1,49 & 1,51 & 1,48 \\
\hline
\end{tabular}




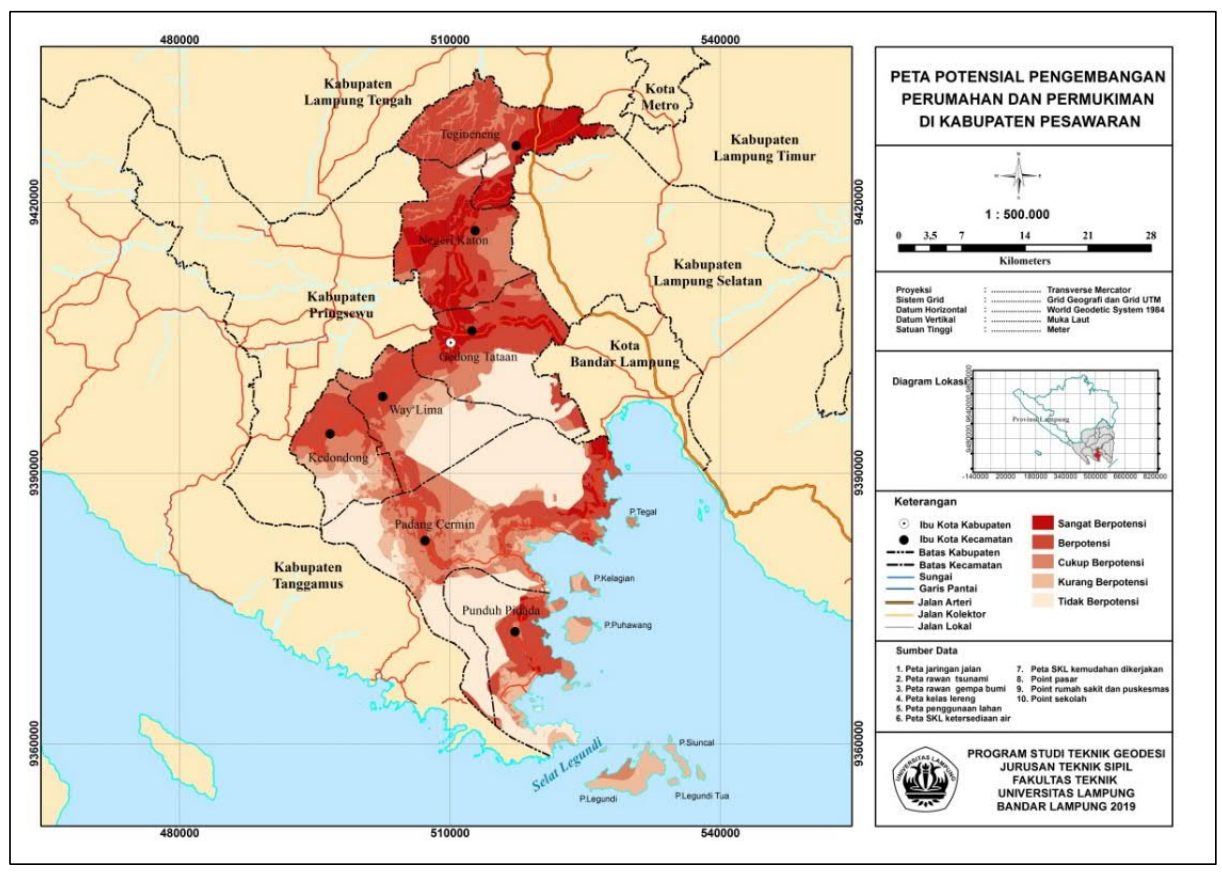

Gambar 1. Peta Potensi Pengembangan Kawasan Perumahan dan Permukiman di Kabupaten Pesawaran Provinsi Lampung

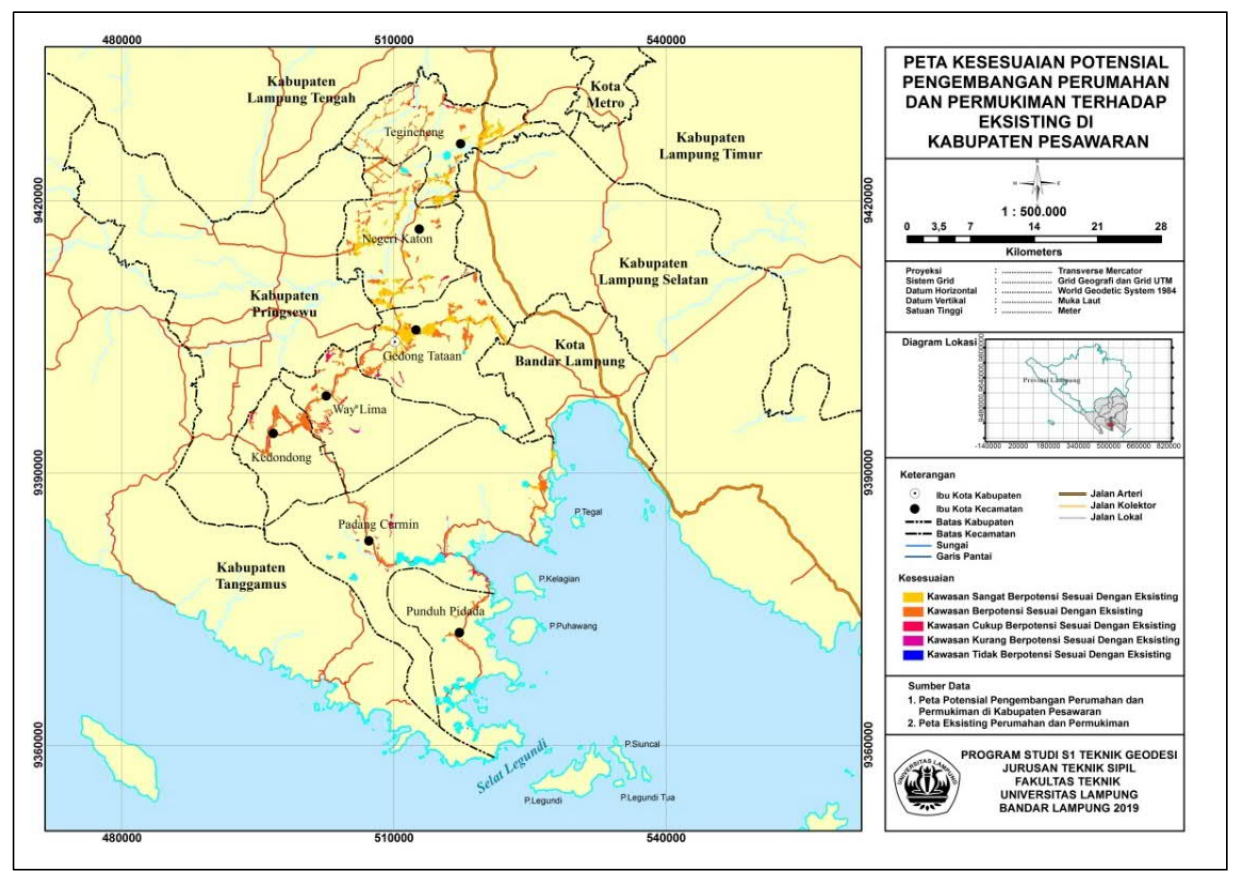

Gambar 2. Peta Kesesuaian Potensial Pengembangan Perumahan dan Permukiman Terhadap Eksisting di Kabupaten Pesawaran Provinsi Lampung 